\title{
Margaret McCartney: Bring high street pharmacists into the NHS
}

\author{
Margaret McCartney, general practitioner
}

Glasgow

Community pharmacists should work directly for the NHS, mainly in general practices, and not in private chemist stores. This intervention would be radical and unusual, directing people back towards the NHS rather than to private business.

I visited a local chemist's shop recently. On the counter were some healing crystals and on the shelves a plethora of homeopathic preparations. Nearby a sign, in official NHS Pantone 300 blue, offered NHS services such as stop smoking and repeat prescription orders.

Most pharmacies now have little rooms to accommodate confidential conversations, but a lot of wares-from cough mixtures $^{1}$ to topical agents for insect bites ${ }^{2}$ - do brisk trade without good evidence of effectiveness.

Pharmacists in the community have been plagued by corporate conflicts of interest in much the same way as have GPs under the Quality and Outcomes Framework, pushed to meet targets for drug reviews even when inappropriate. ${ }^{3}$ Many pharmacists working for large chains are demoralised, as happens to us all when judged by standards that we know are not in patients' best interests.

The NHS 111 system directs many patients to pharmacists. In some areas pharmacists are already working in GP surgeries. Many things that GPs do could be done by pharmacists, from helping with drug reviews and checking inhaler technique to dealing with inquiries about out-of-stock drugs (a continual source of on-call time wasting).

Teaming up with a pharmacist employed by and sited inside a private company are the vested interests of the employer and disrupted communications back to the NHS.
Corporate pharmacy chains often restrict which wholesalers they use, creating work for the NHS. For example, this week a pharmacy phoned me to say that it had run out of lithium and asked whether I could prescribe an alternative. But a different pharmacy, with a different supplier, had no difficulty dispensing the drug. The costs of these inefficiencies are transferred back to patients and swallowed by the NHS. The sign might say "NHS pharmacy," but it is Pantone 300 blue lipstick on a corporate pig.

As GPs move to a contract with a lighter form of the Quality and Outcomes Framework, ever closer to a salaried rather than a contractor model, we should reassess the situation. If remote general practices can dispense, practices with a pharmacist working on the same team most certainly can.

The idea that private companies should do NHS dispensing ignores the uncounted problems of corporate firms. Could we at least consider testing the idea of bringing high street pharmacists into the NHS fold?

Competing interests: See www.bmj.com/about-bmj/freelancecontributors/margaret-mccartney.

Provenance and peer review: Commissioned; not externally peer reviewed.

1 Smith SM, Schroeder K, Fahey T. Over-the-counter (OTC) medications for acute cough in children and adults in community settings. Cochrane Database Syst Rev 2014;11:CD001831.pmid:25420096.

2 Management of simple insect bites: where's the evidence?Drug Ther Bull 2012;50:45-8. doi:10.1136/dtb.2012.04.0099 pmid:22495051.

3 Chakrabortty A. How Boots went rogue. Guardian 2016 Apr 13. www.theguardian.com/ news/2016/apr/13/how-boots-went-rogue.

Published by the BMJ Publishing Group Limited. For permission to use (where not already granted under a licence) please go to http://group.bmj.com/group/rights-licensing/ permissions 